\title{
Gastric Carcinoma
}

National Cancer Institute

\section{Source}

National Cancer Institute. Gastric Carcinoma. NCI Thesaurus. Code C4911.

A malignant epithelial tumor of the stomach mucosa. The vast majority of gastric carcinomas are adenocarcinomas, arising from the gastric glandular epithelium. 